\title{
Fine mapping of the Rrs1 resistance locus against scald in two large populations derived from Spanish barley landraces
}

Kerstin Hofmann ${ }^{1}$, Cristina Silvar ${ }^{2,3}$, Ana M Casas ${ }^{3}$, Markus Herz ${ }^{1}$, Bianca Büttner ${ }^{1}$, M Pilar Gracia $^{3}$, Bruno Contreras-Moreira ${ }^{3,4}$, Hugh Wallwork ${ }^{5}$, Ernesto Igartua ${ }^{3}$, Günther Schweizer ${ }^{1}$

${ }^{1}$ Bavarian State Research Center for Agriculture, Institute for Crop Science and Plant Breeding, D-85354 Freising, Germany.

${ }^{2}$ current: Department of Animal and Plant Biology and Ecology, University of Coruña, E-15071 A Coruña, Spain.

${ }^{3}$ Aula Dei Experimental Station, CSIC, Department of Genetics and Plant Production, E-50059 Zaragoza, Spain.

${ }^{4}$ Fundación ARAID, Zaragoza, Spain.

${ }^{5}$ South Australian Research and Development Institute, SARDI, Plant Research Centre, Hartley Grove, Urrbrae, South Australia 5064. Also: School of Agriculture, Food and Wine, University of Adelaide, Urrbrae, South Australia 5064.

Kerstin Hofmann ${ }^{1}$ and Cristina Silvar ${ }^{2}$ contributed equally to this publication

Corresponding Author: Schweizer, G. ${ }^{1}$

Tel.: +49 8161714065

Fax: +49 8161714514

E-mail: Guenther.Schweizer@lfl.bayern.de 


\section{Key Message}

In two Spanish barley landraces with outstanding resistance to scald the Rrs $1_{R h 4}$ locus was fine mapped including all known markers used in previous studies and closely linked markers were developed.

\section{Abstract}

Scald, caused by Rhynchosporium commune, is one of the most prevalent barley diseases worldwide. A search for new resistance sources revealed that Spanish landrace-derived lines SBCC145 and SBCC154 showed outstanding resistance to scald. They were crossed to susceptible cultivar Beatrix to create large DH-mapping populations of 522 and $416 \mathrm{DH}$ lines that were scored for disease resistance in the greenhouse using two $R$. commune isolates. To ascertain the pattern of resistance, parents and reference barley lines with known scald resistance were phenotyped with a panel of differential $R$. commune isolates. Subpopulations were genotyped with the Illumina GoldenGate 1,536 SNP-Assay and a large QTL in the centromeric region of chromosome 3H, known to harbour several scald resistance genes and/or alleles, was found in both populations. Five SNP markers closest to the QTL were converted into CAPS markers. These CAPS markers, together with informative SSR markers used in other scald studies, confirmed the presence of the Rrs1 locus. The panel of differential scald isolates indicated that the allele carried by both donors was $R r s 1_{R h 4}$. The genetic distance between $R r s 1$ and its flanking markers was 1.2 cM (11_0010) proximally and $0.9 \mathrm{cM}\left(11 \_0823\right)$ distally, which corresponds to a distance of just below $9 \mathrm{Mbp}$. The number and nature of scald resistance genes on chromosome $3 \mathrm{H}$ are discussed. The effective Rrs1 allele found and the closely linked markers developed are already useful tools for molecular breeding programs, and provide a good step towards the identification of candidate genes.

\section{Keywords}

Rhynchosporium commune, $R$. secalis, Hordeum vulgare, SBCC, Rrs1, scald, leaf blotch

\section{Abbreviation}

SBCC, Spanish Barley Core Collection; SARDI, South Australian Research and Development Institute; BOPA1, Barley Oligonucleotid Pool Assay; rs, Rhynchosporium secalis, DH, doubled haploid 


\section{Introduction}

The fungal disease leaf blotch or leaf scald, caused by the hemibiotrophic haploid fungus

Rhynchosporium commune (formally R. secalis, Zaffarano et al. 2011), is one of the most prevalent barley diseases worldwide, particularly in the cool and semi-humid barley growing regions (Zhan et al. 2008). Yield losses attributed to this pathogen commonly range around 5-10\%, though losses of up to $40 \%$ have been reported (Paulitz and Steffenson 2011). The fungus and its interaction with barley have been thoroughly reviewed by Zhan et al. (2008) and are described in more detail in Thirugnanasambandam et al. (2011). A comprehensive profile of $R$. commune is shown in Avrova and Knogge (2012).

Barley scald is currently controlled by means of agronomic practices, chemical control and genetic resistance (Avrova and Knogge, 2012). In northern Europe, leaf scald is principally controlled by fungicide treatment, although increasing bans on pesticides in the EU reduce the opportunities to achieve good control of pathogens in cereals exclusively through the application of fungicides (Hillocks 2012). The most sustainable and cost-efficient way to reduce the disease is growing resistant cultivars. The main drawback of both disease management strategies is, that $R$. commune is a highly variable pathogen and able to overcome new fungicides and resistances very quickly (Shipton et al. 1974; Xi et al. 2000; Zhan et al. 2008; Avrova and Knogge 2012). Even in scald resistant cultivars the fungus is sometimes able to sporulate to a small extent, without clear symptoms (Ayres and Owen 1971; Thirugnanasambandam et al. 2011, Zhan et al. 2012). Therefore, the demand for resistance genes and/or alleles is still high, as is the need for suitable markers to design more efficient breeding programs and gene pyramiding (Looseley et al. 2012).

The number and nomenclature of scald resistance genes in barley is not settled, though efforts to clarify the different QTLs and genes have simplified the field and in 2002 Bjørnstadt et al. summarized the accepted new Rrs classifications (Bjørnstadt et al. 2002). Following one of the most recent and thorough reviews on this subject, by Zhan et al. (2008), nine major resistance genes have been identified (designated with an Rrs prefix), as well as many QTL, at least seven of them in genomic locations clearly distinct from the major genes. The sources of resistance are either barley varieties (Dyck and Schaller 1961; Habgood and Hayes 1971; Schweizer et al. 1995, 2004; Graner and Tekauz 1996; Cheong et al. 2006; Wagner et al. 2008), landraces (Dyck and Schaller 1961; Garvin et al. 2000; Patil et al. 2003), Hordeum vulgare ssp. spontaneum (Garvin et al. 2000; Genger et al. 2003; von Korff et al. 2005; Yun et al. 2005) and even one gene from H. bulbosum (Pickering et al. 2006).

The Rrs1 locus was the first to be discovered and has been repeatedly mapped to chromosome $3 \mathrm{H}$ (Thomas et al. 1995; Graner and Tekauz 1996; Williams et al. 2001; Grønnerød et al. 2002; Genger 
et al. 2003) with more than eleven identified alleles (Bjørnstadt et al. 2002). However, it is still not clear whether Rrs1 is a collection of several R-genes close to each other or several alleles of the same gene. In fact, the number and location of scald resistance genes on chromosome $3 \mathrm{H}$ of barley is an issue still under debate (Bjørnstad et al. 2002; Wallwork and Grcic 2011). Dyck and Schaller (1961) described two closely linked genes Rh3 and Rh4 which later Habgood and Hayes (1971) described as alleles of the same gene $\left(R h\right.$ and $\left.R h^{4}\right)$. Recent studies (Wallwork and Grcic 2011) identified at least two distinct patterns of reaction to scald caused by the gene(s) located close to the centromere on $3 \mathrm{H}$, which are distinguishable using panels of differential isolates and cultivars. Patil et al. (2003) mapped a second resistance locus, named $\operatorname{Rrs}_{\mathrm{C} 111549}, 22 \mathrm{cM}$ distal to $\operatorname{Rrs} 1$ on chromosome 3HL. Finally, several authors have found that dwarfing genes on the long arm of $3 \mathrm{H}$ have a pleiotropic effect on scald resistance (Jensen et al. 2002; Looseley et al. 2012).

With the exception of Rrs2 (Hanemann et al. 2009), there are no diagnostic markers for any of the scald resistance loci. There are markers closely linked to Rrs1, namely HVM0027 (SSR), MWG680 (RFLP) and STS_agtc17 (Patil et al. 2003), but they still show recombination with each other and with the resistance gene itself, making them unreliable for precise marker assisted selection. This is further aggravated by the centromeric region position of Rrs1 exhibiting very low recombination frequency. Phillips et al. (2010) report that about $20 \%$ of all barley genes may be located in centromeric and subcentromeric regions and thus represent genes with limited accessibility based on genetic mapping approaches. And even if tightly linked markers are used for MAS, linkage drag during introgression of these "centromeric" genes will be large.

To this day no single, publically available map that integrates all the known SSR and STS markers around the Rrs1 locus exists. The development of integrated maps and tightly linked markers is recommended to provide more diagnostic markers for scald resistance loci to molecular breeding programs and to analyse genetic haplotypes for association studies. For these reasons, a precise location of "Rrs1" in a dense map including as many informative markers as possible is a sensible research objective, especially in term of combining older SSR with newly developed SNP markers (Illumina) in one map.

Another requisite to improve breeding for disease resistance is the identification of additional resistance sources, preferably in the primary genepool of $H$. vulgare. Collections of landraces represent valuable resources containing broad genetic variability for numerous agronomically important traits. One of these collections is the Spanish Barley Core Collection (SBCC), a representative sample of the landraces traditionally cultivated in Spain, comprising 175 genetically diverse genotypes (Igartua et al. 1998; Lasa 2008). The SBCC was evaluated for resistance against multiple pathogens and a remarkably high number of lines $(26 \%)$ presented good resistance to scald 
(Silvar et al. 2010). Two of the highly resistant lines, SBCC145 and SBCC154, were chosen for further investigation and fine mapping of the scald resistance loci in two large DH populations. So, the objectives of the present work were i) to identify the factors underlying the resistance to scald of both SBCC lines, ii) to locate them in a dense map with publicly available markers as well as all known markers used in previous Rrs1 studies, and iii) to develop tightly linked markers suitable for the rapid incorporation of these loci in barley breeding programs.

\section{Materials and Methods}

\section{Plant material and fungal isolates}

The lines SBCC145 and SBCC154, from the SBCC, were selected for their outstanding resistance to R. commune (Silvar et al. 2010). SBCC145 is a six-rowed intermediate barley line (with a mild vernalization requirement) and is also resistant to powdery mildew (Silvar et al. 2011), whereas SBCC154 is a two-rowed facultative barley. Both lines were crossed with Beatrix (Viskosa/Pasadena), a cultivar from the German breeder Nordsaat. Beatrix is a two-rowed spring barley with good malting quality and is highly susceptible to scald.

For scald resistance and further mapping studies, two doubled haploid (DH) populations consisting of 522 (SBCC145×Beatrix) and 416 DH lines (SBCC154×Beatrix) were generated by antherculture from the $F_{1}$ generation. From them, subpopulations of 190 and $168 \mathrm{DH}$ lines, respectively, were created for whole genome genotyping and QTL analysis. Lines for each subpopulation were selected randomly based on the expression of a clear phenotype in response to scald infection. In addition to the susceptible parent Beatrix, the two-rowed German spring barley varieties, Steffi (Saatzucht Ackermann, Irlbach) and Alexis (Saatzucht Breun, Herzogenaurach) were used as scaldsusceptible references for phenotyping. A set of eleven additional barley accessions with one or two known resistance loci was used for comparison purposes on the level of resistance of SBCC145 and SBCC154 (Table 1).

Five genetically diverse isolates of $R$. commune (S147-1, Rhy17, Rhy174, UK7, LfL07) from the collection held at the Bavarian State Research Center for Agriculture in Freising (Germany) were used to assess the level of resistance of Spanish lines in comparison with the set of eleven barley accessions. Isolate 271 was used to phenotype the entire DH populations and isolate LfL07 was used for additional phenotyping of the subpopulations used for whole genome genotyping. Isolates 271 and LfL07 produced similar reactions on the parents of both populations. The $R$. commune isolates were cultivated in liquid media in the dark at $15^{\circ} \mathrm{C}$. The spore suspension was produced by planting pea-sized pieces of mycelium on lima bean agar to induce the formation of spores. Spores 
were harvested after two weeks of growth, at $15^{\circ} \mathrm{C}$ in the dark, by scraping culture plates with $5 \mathrm{ml}$ RO water and then were diluted to a concentration of $2 \times 10^{5}$ spores $/ \mathrm{ml}$ (Hanemann et al. 2009). Two additional isolates of $R$. commune, 332a and 385 from the collection held at the South Australian Research and Development Institute (SARDI) in Adelaide were tested in Australia against the Spanish parent lines and four of the eleven barley accessions. These two isolates are able to discriminate between specific virulence patterns of Rrs1 alleles found in the centromeric region of chromosome 3H (Wallwork and Grcic 2011). At SARDI, the two isolates were cultivated following the procedures detailed in Wallwork and Grcic (2011) using an end concentration of $1 \mathrm{x}$ $10^{6}$ spores $/ \mathrm{ml}$ for inoculation.

\section{Resistance assessment}

At Freising, an assessment of resistance to R. commune for the parents, checks, and the two populations was carried out according to Schweizer et al. (2004) and Hanemann et al. (2009) with two isolates (271 and LfL07). Each trial consisted of four individual plants of each DH line. Plants were grown in the greenhouse at $18^{\circ} \mathrm{C}$ for three weeks to the early three-leaf-stage and then sprayed with a spore suspension adjusted to a concentration of 200,000 spores $/ \mathrm{ml}$. Immediately after spray inoculation the plants were maintained in the dark with $100 \%$ humidity for 48 hours. Approximately at 14-21 days after inoculation, scald symptoms were rated on the second leaf of each individual plant three times every other day according to Jackson and Webster (1976), using half steps for better discrimination. The data presented in this work (Fig. 1) are the average score of all four plants per DH line and isolate. The German varieties Steffi and Alexis were used as scald susceptible reference cultivars. At SARDI/Adelaide, the tests were also conducted under controlled environmental conditions, following the procedures explained in detail in Wallwork and Grcic (2011). Merging the data of both scales leads to $\mathrm{R}=0, \mathrm{R} / \mathrm{MR}=1, \mathrm{MRMS}=2, \mathrm{~S} / \mathrm{MS}=3$ and $\mathrm{S}=4$.

\section{Genotyping}

Genomic DNA was isolated from frozen barley leaves by using the NucleoSpin Plant II Minikit (Macherey-Nagel, Düren, Germany) or according to Behn et al. (2004). In order to check for the association between resistance and markers previously linked to scald resistance in other populations, the populations were genotyped with the populations were genotyped with HVM0027 (Ramsay et al. 2000) and STS_agtc17, for Rrs1 (Grønnerød et al. 2002; Patil et al. 2003) and with HVM0060 for Rrs4 (Patil et al. 2003). To identify polymorphic markers surrounding the known Rrs1 locus, SBCC145, SBCC154 and Beatrix were screened with all available SSRs (Ramsay et al. 2000; Li et al. 2003; Rostoks et al. 2005; Stein et al. 2007; Varshney et al. 2007) and SNPs 
(Rostoks et al. 2005; Stein et al. 2007) in the centromeric region of chromosome 3H. Marker for Rrs15 (Gems13; Schweizer et al. 2004) and Rrs2 (Atlas14, AcriCaps; Hanemann et al. 2009) were not polymorphic in the present populations.

QTL mapping was conducted to check for scald resistance loci over the whole genome. With this purpose, both subpopulations of 190 and $168 \mathrm{DH}$ lines described above were genotyped with the 1,536-SNP Illumina GoldenGate Oligonucleotid Pool Assay (Barley OPA1 or BOPA1) (Close et al. 2009) as described previously for SBCC145×Beatrix (Silvar et al. 2011). Five BOPA1 markers (11_0010,11_0205, 11_0315, 11_0823 and 11_1476) that were closely linked to the resistance QTL (most likely Rrs1) were converted into CAPS markers (Table S1), and used to genotype the entire populations. These markers were positioned in the Genome Zipper (Mayer et al. 2011) and in the barley physical map to realize the size of the genomic region of interest. Their position was determined by running BLASTN (Altschul et al. 1997) with options -task megablast -dust no, against all anchored contigs and genes (datasets $\mathrm{AC} 1, \mathrm{AC} 2$ and $\mathrm{AC} 3$ ) of the barley physical map (IBSC 2012), available from ftp://ftpmips.helmholtz-muenchen.de/plants/barley/public_data/.

\section{Linkage and QTL analysis}

Single and integrated linkage maps were constructed with JoinMap 4.0 (van Ooijen 2006), using Kosambi's map function (Kosambi 1944) and a minimum logarithm of the odds ratio (LOD score) of 5. A map with just BOPA1 markers for the subpopulation SBCC145×Beatrix was previously constructed for all seven chromosomes (Silvar et al. 2011). For chromosome 3H, a detailed consensus map comprising all SSRs and the five closest BOPA markers was built using the information from the entire populations.

QTL analysis was performed using MapQTL 5.0 (van Ooijen 2004). The interval mapping (IM) procedure was used in a preliminary analysis to identify major QTLs and to detect significantly associated markers. These markers were then used as cofactors in a multiple QTL model (MQM) (Jansen and Stam 1994). MQM was repeated iteratively by adding significant 'peak markers' at each step as cofactors, until a stable LOD profile was reached. The LOD threshold for detecting QTLs was calculated by a permutation test with 1,000 iterations and a genome-wide significance level of 0.05 . This procedure was followed for the whole genome scans of the subpopulations genotyped with BOPA1, and also for chromosome $3 \mathrm{H}$ for the whole populations. The interaction between QTLs was analysed by means of analysis of variance, including as sources of variation the closest markers to the QTL peaks, and calculated using the unbalanced anova routine implemented in Genstat 14 (VSN International 2011). Rrs1 was also mapped as a binary trait, assigning a score of 0 (resistant) to lines with average disease resistance scores between 0 and 1.9, and a score of 1 to lines with disease scores between 2.0 and 4.0. 


\section{Results}

\section{Disease resistance}

In a first step, the scald resistant lines SBCC145 and SBCC154 out of the Spanish Barley Core Collection were phenotyped for disease resistance with five different $R$. commune isolates (Table 1) along with another eleven reference donors for scald resistance $\left(\operatorname{Rrs} 1_{R h 4}, \operatorname{Rrs} 2, \operatorname{Rrs} 15, \operatorname{Rrs} 1, \operatorname{Rrs} 13\right)$ and three highly susceptible cultivars (Alexis, Barke, Steffi). All resistance donors showed mild disease symptoms to at least one R. commune isolate in the form of small isolated necrosis on the leaf surface or leaf margins after infection (no large lesions), whereas cultivar Pewter, Atlas, Escaldadura15 and CIho 2235 showed weak symptoms with all isolates. Mean infection scores of the resistant accessions with these isolates ranged from 0.0 to 0.9 . SBCC145 and SBCC154 had some of the lowest scores, with means of 0.2 and 0.2 , respectively. Only the accessions with more than one resistance locus (Atlas46, Osiris, PI 452395, CIho 3515, Triton) showed comparable infection scores $(0.1-0.2)$. Accessions with only one resistance locus and without $R r s 1_{R h 4}$ like Atlas, CIho 2235, CIho 8288, Pewter and WW Glabron on the other hand were less resistant (0.40.9). The susceptible cultivars reached mean infection scores of 4.0 (Table 1). An additional independent phenotyping of the landraces SBCC145 and SBCC154 and reference lines with the differential scald isolates 332a and 385 at SARDI revealed distinct patterns of resistance (Table 1), by which all resistant lines with the assumed Rrs $1_{R h 4}$ locus (SBCC145, SBCC154, Osiris and CIho 3515) were resistant to isolate 332a and susceptible to isolate 385 (Wallwork and Grcic, 2011). In case of CIho 3515 the R-gene Rrs13 improved the infection score.

The whole DH mapping populations SBCC145×Beatrix $(\mathrm{n}=522)$ and SBCC154×Beatrix $(\mathrm{n}=416)$ were phenotyped for scald resistance with the R. commune isolate 271 (Fig. 1). Infection scores for the parental lines were on average 0.0 for SBCC145, 0.0 for SBCC154 and 4.0 for Beatrix. Mean infection scores for the populations were 2.63 and 2.32 for SBCC $145 \times$ Beatrix and SBCC154×Beatrix, respectively. The segregation ratios were $215(\mathrm{R}): 305(\mathrm{~S})$ for SBCC145×Beatrix and 149 (R): 264 (S) for SBCC154×Beatrix, with 0-1.9 considered resistant (R) and 2.0-4.0 being susceptible (S) in both cases. Deviation from the expected 1:1 segregation was significant $\left(\chi^{2}\right.$ test $)$ at 0.01 for both populations $\left(\chi^{2}=15.58\right.$ for SBCC145 $\times$ Beatrix, $\chi^{2}=32.02$ for SBCC154×Beatrix). The bimodality observed points to the presence of one large QTL, although the deviation from a 1:1 segregation might suggest the presence of additional minor QTLs (Fig. 1). To account for this, two randomly selected smaller subpopulations from SBCC145×Beatrix ( $\mathrm{n}=190)$ and SBCC154×Beatrix ( $\mathrm{n}=168$ ) were used (s. Material and Methods) to perform whole genome QTL analysis with the Illumina Barley OPA1 chip. In addition to the disease scoring with $R$. 
commune isolate 271 , the subpopulations were additionally phenotyped with the scald isolate LfL07, and the infection scores for the parental lines were 0.0 for SBCC145, 0.0 for SBCC154 and 4.0 for Beatrix. Mean infection scores for the subpopulations were 2.5 and 2.4 for SBCC145×Beatrix and SBCC154×Beatrix, respectively. Segregation ratios were $83(\mathrm{R}): 107(\mathrm{~S})$ and 62 (R): 80 (S) for SBCC145×Beatrix and SBCC154×Beatrix, respectively (Fig. S1). Segregation did not deviate from 1:1 at a level of 0.01 for both subpopulations $\left(\chi^{2}=3.03\right.$ for SBCC $145 \times$ Beatrix and $\chi^{2}=2.28$ for SBCC $154 \times$ Beatrix).

\section{Mapping of the scald resistance locus}

Both mapping populations were genotyped with markers linked to previously published scald resistance genes and, as a preliminary result, the main scald resistance locus in both populations was linked to markers HVM0027 and STS_agtc17, close to the centromeric region of chromosome $3 \mathrm{H}$. This location suggested that the Rrs1 locus was the major factor underlying the resistance of both SBCC lines. Consequently, publically available markers, including all known markers used in previous studies to locate the Rrs1 locus, and those close to the centromeric region of chromosome $3 \mathrm{H}$ were screened for polymorphism between the parental lines and used for map construction (Table S2).

In a second step, a whole genome mapping of the SBCC $145 \times$ Beatrix subpopulation was performed with Illumina-BOPA1 as reported in Silvar et al. (2011). Regarding the SBCC154×Beatrix subpopulation, 636 out of 1,536 SNPs were polymorphic between SBCC154 and Beatrix and were used for the construction of the linkage map, which comprised a total length of 1,256.9 cM (Fig. S2). QTL analyses were then carried out for both SBCC145×Beatrix and SBCC154×Beatrix subpopulations. A major QTL was detected in both subpopulations for both isolates, with LOD scores between 37.8 and 141.3 on chromosome $3 \mathrm{H}$, close to the centromeric region, and in accordance to the preliminary marker results (Fig. S3, Table 2). Two additional minor QTL were detected for isolate 271 on chromosomes $2 \mathrm{H}$ and $4 \mathrm{H}$. The first one was present in both subpopulations, with LOD scores of 3.6 (SBCC145×Beatrix) and 2.8 (SBCC154×Beatrix) (Table 2). The second minor QTL on chromosome $4 \mathrm{H}$ was detected only in the SBCC145×Beatrix subpopulation, with a LOD score of 10.6 (Table 2). There was no significant interaction among QTLs in the population SBCC154×Beatrix. However, in SBCC145×Beatrix, a significant three-way interaction between the three QTLs was detected for resistance to isolate 271. Also, the interactions of the two minor QTL with the large QTL on $3 \mathrm{H}$ were close to the significance threshold ( $P$ values of 0.05 and 0.07 ). This was caused by the more conspicuous effect of the minor QTL in presence of the resistant allele at the $3 \mathrm{H}$ large QTL (Table 3). 
Using the genotypic information of both subpopulations, an integrated map of chromosome $3 \mathrm{H}$ was constructed. Five BOPA1 markers that mapped closest to the resistance locus $\left(11 \_1476,11 \_0010\right.$, 11_0823, 11_0205 and 11_0315) were converted into CAPS markers (Table S1) and mapped in the population SBCC145×Beatrix $(n=522)$ and SBCC154×Beatrix $(n=350)$ in which they were polymorphic (all five in SBCC154×Beatrix, all but 11_0010 and 11_0823 in SBCC145×Beatrix). A high confidence consensus map of chromosome $3 \mathrm{H}$ using the information of all lines of both populations was constructed (Fig. 2). It covered a region of $49.1 \mathrm{cM}$ around the resistance locus. Four BOPA markers (11_0010, 11_0823, 11_0205, 11_0315) mapped into the gap between Rrs1 and the closest SSR (Bmag0006) or STS (Falcon and STSagtc17) markers, whereas SNP 11_1476 mapped together with the closest proximal SSR GBM1242. The genetic distance in the consensus map of the interval comprising the resistance locus was $2.1 \mathrm{cM}$.

In the Genome Zipper (Mayer et al. 2011) the region encompassing markers 11_0010 and 11_0823 comprised the modest number of 16,12 and 12 genes of Brachypodium, rice and sorghum, respectively. Including 11_0315 as the safe lower flanking marker, as it is present in the two populations, increased the number of syntenic genes in the Genome Zipper to 26, 22 and 23, respectively, for the three species.

The CAPS markers were placed in the physical map of barley. Sequences corresponding to genetic markers 11_0010(1_0005) and 11_0823 (1_0728) were obtained from Close et al. (2009). The matched contig for 11_0010 had coordinate 377656880 in Morex, Bowman and Barke physical maps, which corresponds to a genetic distance of $53.26 \mathrm{cM}$ in chromosome $3 \mathrm{H}$. However, marker 11_0823 was assigned to two different, but close, positions: 383952360 in Morex and Bowman, and 386536520 in Barke (54.21cM and $54.53 \mathrm{cM}$, respectively). We decided to take the largest $(8.9 \mathrm{Mb})$ defined interval in order to identify anchored genes within it. Although the barley physical map still does not resolve the fine order of genes, a total of 30 high confidence genes were found, and their annotations retrieved from the file barley_HighConf_genes_MIPS_23Mar12_HumReadDesc.txt. CAPS marker 1_0158 (11_0205) was not located, neither in Genome Zipper nor in the physical map. Marker 11_0315 (1_0281) corresponded to position $55.15 \mathrm{cM}, 389321560 \mathrm{bp}$ in Bowman and Barke physical maps, and may be used as a safe external flanking position for further fine mapping.

\section{Discussion}

Previous screening of the Spanish Barley Core Collection revealed that several landrace-derived lines were highly resistant to the R. commune isolate Sachs 147-1 (Lasa 2008; Silvar et al. 2010). Two of the most resistant lines, SBCC145 and SBCC154, were selected to further investigate the genetic basis underlying their outstanding resistance to scald using two large DH populations from 
crosses with the susceptible cultivar Beatrix. The goal was the development of tightly linked markers for selective incorporation of these loci in barley breeding programs.

An extensive screening of both populations with publicly available markers revealed that the resistance locus in both populations co-located with the Rrs1 resistance gene on 3HL, close to the centromeric region. The distorted ratios of segregation for resistant and susceptible plants were probably caused by an underlying distortion of allelic frequencies in the region of the main QTL in $3 \mathrm{H}$, and not by the presence of more than one major QTL. All SNPs analysed in the area surrounding this QTL presented distorted allelic frequencies in both populations, between 0.34 and 0.40 for the SBCC145 allele and between 0.31 and 0.39 for the SBCC154 allele, in a region encompassing 20 and $40 \mathrm{cM}$, respectively (Table S3). Such deviations are not unusual for DH populations derived from anther culture (Graner and Tekauz 1996, Sayed et al. 2002). Therefore, it is safe to assume that this major resistance gene locus was the main cause for the outstanding resistance in both populations, as shown for the CAPS marker 11_0205 in Fig. S1A, showing a distorted segregation at a ratio of about $40 \%$ resistant to $60 \%$ susceptible lines in both populations. Besides the main QTL on 3H at the Rrs1 locus, two minor QTLs were found in this work. A review of common markers across several maps suggests that the two minor QTLs found in this work may have been detected by other studies. The two markers closest to the QTLs on 2H (Table 2) might be marking the same region, even though they are 11 and $15 \mathrm{cM}$ apart in each population. These QTL also lie within the region where Rrs15 was detected by Schweizer et al. (2004). In that same region, von Korff et al. (2005) and Wagner et al. (2008) found QTL for scald resistance coming from wild and cultivated barley, respectively. The Rrs15 locus was further checked with linked markers for their influence on scald disease in both populations. The results confirmed the region, but did not point to the presence of a functional allele for the $\operatorname{Rrs} 15_{8288}$ major resistance gene (data not shown). The second QTL on chromosome 4H could mark the position of a QTL detected by von Korff et al. (2005), flanked by HVM0013 and GMS0089 on bin 5 of $4 \mathrm{H}$.

The presence of an interaction effect between the three loci detected in SBCC145 $\times$ Beatrix and isolate 271 could be caused by a mathematical artefact. Three of the haplotypes showed in Table 3 , $a b b, b a b$ and $b b b$, present mean disease scores very close or equal to the maximum (4.0). Only when the "resistant" alleles for two minor QTL were present at the same time, was their combined effect noticeable. It is possible that we were not able to discriminate visually among plants belonging to these classes, all of them highly susceptible, presenting very large areas of the leaves infected. At the other end of the spectrum, the most resistant plants (i.e. plants with a "resistant" allele at the 3H QTL), it was easier to discriminate between different degrees of attack. For example, it was easy to distinguish between plants covered with scald on $1 \%$ of the surface vs. 
plants covered by scald on 5\% of the surface. But it was very difficult to differentiate between leaves that were covered by disease spots on $81 \%$ or $85 \%$ of the surface. In both cases, the same difference in percentage cannot be equally detected.

Coming to the major QTL on chromosome 3HL, we found that this locus was responsible for most of the genetic and phenotypic variation in both populations, at coincident positions. SSR- and BOPA-derived CAPS-markers confirmed the Rrs1 locus in both Spanish landrace derived lines as the main candidate for the outstanding resistance level to scald.

Formerly known as the $R h-R h 3-R h 4$ locus, $R r s 1$ was the first scald resistance gene to be reported (Dyck and Schaller 1961; Starling et al. 1971). Graner and Tekauz (1996) identified a dominant resistance gene and located it in an RFLP based linkage map of chromosome 3HL near the centromere, in the progeny of the DH population Igri $\times$ Triton (52 DH lines). In the work by Graner and Tekauz (1996), several RFLP markers co-segregated with the resistance locus Rrs1. From one of those RFLPs the authors developed the co-dominant STS marker cMWG680. The close association of this marker, or the original RFLP (MWG680), has been repeatedly found in the literature (Grønnerod et al. 2002; Genger et al. 2003; Patil et al. 2003). The SNP marker 11_0315, $2.4 \mathrm{cM}$ distal to Rrs1 (Fig. 2) was actually developed from the same EST as cMWG680, so it can be considered to map at the same location for practical purposes. Our position for SNP 11_0315 is consistent with the position of cMWG680 in the four previous studies mentioned. Further investigations of Patil et al. (2003) identified the Rrs1 resistance locus in the DH population CI1 1549 $\times$ Ingrid. The locus was roughly mapped to the centromeric region of chromosome $3 \mathrm{H}$. The precision of the mapping was impaired by the population size as well as by the presence of a second resistance locus Rrs4 on the same chromosome. But this second locus was linked to the SSR marker HVM0060 mapping about 22cM distal to Rrs1. Our consensus map with over 800 DH-lines (Fig. 2) clearly places 11_0315 and HVM0060 $23 \mathrm{cM}$ apart, about the same distance found in that study, and very similar to the one presented in the dense map of Aghnoum et al. (2010). All these distances are very consistent and, given the high precision of the map of chromosome $3 \mathrm{H}$ presented in this work, we can rule out that Rrs4 is segregating in our populations.

The formerly known $R h-R h 3-R h 4$ locus, renamed Rrs1 in 2002 could be a complex locus for scald resistance. Bjørnstad et al. (2002) identified 11 alleles at the Rrs1 locus and suggested that there should be more. Recently, Li and Zhou (2011) described two new QTL at the same location in the TX9425 $\times$ Franklin and Yerong $\times$ Franklin DH populations. The Franklin allele provided resistance to one population but susceptibility to the other population. The Yerong allele on $3 \mathrm{H}$ showed much better resistance to scald than the Franklin allele, which had not been reported before. These results confirm the presence of an allelic series at this locus, with functional differences at least in some 
cases. The QTL analyses reported in this work suggest that both SBCC145 and SBCC154 may carry a strong allele of the Rrs1 locus like Osiris, Yerong, La Mesita and CIho3515, and more efficient than those found in other cultivars (Table 1). Actually, Yerong is genetically very closely related to Osiris (Langridge et al. 1996), almost as close as to its parent Malebo (Read and Macdonald 1991).

The existence of one or two scald resistance loci in the centromeric region of $3 \mathrm{HL}$ has not been settled yet. Classical studies by Dyck and Schaller (1961) and Habgood and Hayes (1971), found a few recombinants in crosses involving $R h 3, R h 4$ and other alleles but, according to the latter study, they can not exclude that the recombinants are the result of outcrossing. To settle this issue, new populations of large size involving informative parents should be constructed and studied with a panel of differential scald isolates.

The panel of differential scald isolates derived from the work by Wallwork and Grcic (2011) indicated that the Rrs1 allele carried by both donors was $R r s 1_{R h 4}$. The evaluation of both SBCC parents revealed that they present a virulence pattern close to the resistance traditionally described as Rh4 (Graner and Tekauz 1996), later renamed by Bjørnstad et al. (2002) as Rrs $1_{R h 4}$, to indicate that it belongs to the Rrs1 locus. This resistance seems typical of accessions originating in North Africa or the Western Mediterranean region: CIho 3515 is Spanish, Osiris and Malebo (parent of Yerong) from Algeria and La Mesita is from Egypt, along one of the possible paths of expansion of barley from the Fertile Crescent towards the West (Baba et al., 2011; Igartua et al. 2013). Therefore, it may have evolved in response to pathotypes prevalent in that region.

Besides a large number of known scald resistance genes, barley researchers still find overall differences between spring and winter barley cultivars regarding the level of scald resistance. Zhan et al. (2008) described that winter barley cultivars apparently have much better resistance to $R$. commune than spring barley cultivars. This could be due to the higher selection pressure on winter barley caused by the longer growing season and the longer period of cold and humid weather in fall and early spring. Therefore the process of selection for healthier lines is more distinct than in spring barley. This means that in general, the resistance level in winter barley tends to be on a higher level. Spanish barleys, though sometimes informally described as spring types, are actually winter types with a reduced vernalization requirement (Casao et al. 2011), and are usually sown in autumn. In this case, SBCC145 is a typical example of that kind of genotype. SBCC154 however, is a true spring barley, the only one of the collection showing any degree of resistance to scald, and is probably one of the most resistant spring barleys described in the literature. It may have arisen as a recombination with resistant winter types prevalent in the region. 
To analyse the possible pleiotropic interaction of growth habit and scald, the populations were additionally investigated for a segregating dwarfing gene present on 3HL (as stated by PonceMolina et al. (2012) for SBCC145×Beatrix, and by E. Igartua, unpublished), but no effect of this gene on scald resistance was observed. In this regard, a scald resistance QTL was detected based on field observations and interpreted as a pleiotropic effect of growth habit (Jensen et al. 2002; Looseley et al. 2012). Prostrate plants, carrying the dwarfing allele, were more prone to acquire the disease by spread from rain splashes. In our study, done under controlled conditions, plant architecture did not play a role, but this factor should be taken into account when using this germplasm for breeding.

Besides scald, the SBCC lines are an interesting germplasm resource providing ample variability for several agronomic key traits, directly useful for breeding programs. Within the SBCC145×Beatrix population, lines are segregating for spring and winter types, two and six rows, plant height (Beatrix carries the denso gene, Ponce-Molina et al. 2012), and for resistance to both scald and powdery mildew (Silvar et al. 2011). This diversity ensures that resistance can be selected from amongst a wide variety of plant types.

In summary, we were able to show that the $R r s 1_{R h 4}$ scald resistance locus identified in the lines of the Spanish Barley Core Collection, SBCC145 and SBCC154, is of importance for barley breeding programmes. We were able to ascertain the disease reaction with appropriate differentials and to position closely linked markers for the Rrs1 resistance locus in a complicated chromosomal region with low recombination frequency. The region encompassing the QTL and markers 11_1476, 11_0010, 11_0823, 11_0205 and 11_0315 was mapped with great confidence, based on a large number of individuals and coincides in loci order with the comprehensive consensus map of Muñoz-Amatriain et al. (2011). The consensus map developed, combining SSRs, STS and SNPs, presents an improvement of the definition of the Rrs1 region, including different scald resistance alleles and presents an increase in the precision of the location of Rrs1 compared with previous reports and their respective markers.

The increased polymorphism granted by the use of two different mapping populations allowed a better resolution of the QTL region than would have been attained by one population alone, and pointed to the region flanked by markers 11_0010 and 11_0823 as the most plausible position of the locus. By locating them in the physical map of barley, we were able to define an interval of approximately $8.9 \mathrm{Mb}$, which contains at least 26 high confidence genes, including two chitinases, usually involved in defence reactions (Collinge et al. 2003). Although the region is close to the centromere, showing low recombination, the future identification of a candidate gene through the 
development of a large population to search for recombinants in this region, with only around 30 genes, seems feasible.

For marker based breeding programs, the closely linked BOPA1 SNP-markers have been converted to easy accessible CAPS markers. Unfortunately they are still not perfect diagnostic or functional for the Rrs1 locus. Nevertheless, the easy to handle CAPS markers developed are all closer to the Rrs1 gene than formerly known markers. Therefore we keep looking for further polymorphic markers mapping into the small interval between markers 11_1476 and 11_0205 (which flank the QTL with great certainty in both populations), for which we still found 22 (SBCC145×Beatrix) and 17 (SBCC154×Beatrix) recombinant DH lines. A BSTA (bulked segregant transcriptome analysis) approach and the production of marker selected recombinant $\mathrm{F}_{2: 3}$ lines have been started, and the analyses of map based candidate genes is in process.

\section{Authors Contribution}

The work presented here was carried out in collaboration between all authors. All authors have contributed to, seen and approved the manuscript. $\mathrm{KH}, \mathrm{BB}$ and $\mathrm{AMC}$ were involved in resistance assessment and genotyping. CS and AMC conducted the statistical-/ QTL-analysis. MPG and MH were responsible for the $\mathrm{DH}$ production, the multiplication of the populations and the assessment of field data. BCM conducted the bioinformatics work. HW was responsible for the resistance assessment at SARDI. GS and EI designed the research.

\section{Acknowledgments}

This work was funded by the German BMELV and BLE through the project "Rhynchosporium secalis-resistance in barley (project 28-1-41.009-06) and PLANT KBBE II “ExpResBar” AZ 0315702C and by the Spanish Ministry of Science and Innovation (projects GEN2006-28560-E, AGL2007-63625, RFP2012-00015-00-00, and PLANT KBBE "ExpResBar", EUI2009-04075), and co-funded by the European Regional Development Fund. CS held an I3P contract from CSIC. BCM is supported by Fundación ARAID, Zaragoza, Spain. Barley-SSR markers were kindly provided by Andreas Graner and Marion Röder, IPK Gatersleben. Isolates UK7 and AU2 were kindly provided by W. Knogge, Leibnitz Institute for Plant Biochemistry, Halle. The authors would like to thank Alfred Barth and Alexandra Jestadt for high level of commitment in the laboratory, greenhouse and field and Carlos P. Cantalapiedra for assistance in the work with the physical map of barley. The Grains Research and Development Corporation (GRDC) and SARDI funded the work in Australia.

\section{Conflict of interest}

The authors declare that they have no conflict of interest. 


\section{References}

Aghnoum R, Marcel TC, Johrde A, Pecchioni N, Schweizer P, Niks RE (2010) Basal host resistance of barley to powdery mildew: connecting quantitative trait loci and candidate genes. MPMI 23:91-102

Altschul SF, Madden TL, Schaffer AA, Zhang J, Zhang Z, Miller W, Lipman DJ (1997) Gapped BLAST and PSI-BLAST: a new generation of protein database search programs. Nucleic Acids Res. 25:3389-3402

Avrova A, Knogge W (2012) Rhynchosporium commune: a persistent threat to barley cultivation. Mol Plant Pathol 13:986-997

Ayres G, Owen H (1971) Resistance of barley varieties to establishment of subcuticular mycelia by Rhynchosporium secalis. Trans. Br. Mycol. Soc. 57:233-240

Baba T, Tanno K, Furusho M, Komatsuda T (2011) Allelic variation at the EF-G locus among northern Moroccan six-rowed barleys. Plant Genetic Resources: Characterization and Utilization. 9:240-242

Behn A, Hartl L, Schweizer G, Wenzel G, Baumer M (2004) QTL mapping for resistance against non-parasitic leaf spots in a spring barley doubled haploid population. Theor Appl Genet 108:1229-1235

Bjørnstad Å, Patil V, Tekauz A, Marøy AG, Skinnes H, Jensen A, Magnus H, MacKey J (2002) Resistance to scald (Rhynchosporium secalis) in barley (Hordeum vulgare) studied by nearisogenic lines. I. Markers and differential isolates. Phytopathol 92:710-720

Casao MC, Igartua E, Karsai I, Lasa JM, Gracia MP, Casas AM (2011) Expression analysis of vernalization and day-length response genes in barley (Hordeum vulgare L.) indicates that VRNH2 is a repressor of PPDH2 (HvFT3) under long days. J Exp Bot 6:1939-1949

Cheong J, Williams K, Wallwork H (2006) The identification of QTLs for adult plant resistance to leaf scald in barley. Aust J Agric Res 57:961-965

Close TJ, Bhat PR, Lonardi S, Wu Y, Rostoks N, Ramsay L, Druka A, Stein N, Svensson J, Wanamaker S, Bozdag S, Roose M, Moscou M, Chao S, Varshney R, Szucs P, Sato K, Hayes P, Matthews D, Kleinhofs A, Muehlbauer G, DeYoung J, Marshall D, Madishetty K, Fenton R, Condamine P, Graner A, Waugh R (2009) Development and implementation of high-throughput SNP genotyping in barley. BMC Genomics 10:582

Collinge DB, Kragh KM, Mikkelsen JD, Nielsen KK, Rasmussen U, Vad K (1993) Plant chitinases. Plant J. 3:31-40

Dyck PL, Schaller CW (1961) Inheritance of resistance in barley to several physiologic races of the scald fungus. Can J Genet Cytol 3:153-164

Garvin DF, Brown AHD, Raman H, Read BJ (2000) Genetic mapping of the barley Rrs14 scald resistance gene with RFLP, isozyme and seed storage protein markers. Plant Breeding 119:193-196

Genger RK, Brown AHD, Knogge W, Nesbitt K, Burdon JJ (2003) Development of SCAR markers linked to a scald resistance gene derived from wild barley. Euphytica 134:149-159

Graner A, Tekauz A (1996) RFLP mapping of a dominant gene conferring resistance to scald (Rhynchosporium secalis). Theor Appl Genet 93:421-425

Grønnerød S, Marøy AG, MacKey I, Tekauz A, Penner GA, Bjørnstad A (2002) Genetic analysis of resistance to barley scald (Rhynchosporium secalis) in the Ethiopian line 'Abyssinian' (CI668). Euphytica 126:235-250

Habgood MR, Hayes JD (1971) The inheritance of resistance to Rhynchosporium secalis in barley. Heredity 27:25-37

Hanemann A, Schweizer GF, Cossu R, Wicker T, Röder MS (2009) Fine mapping, physical mapping and development of diagnostic markers for the Rrs2 scald resistance gene in barley. Theor Appl Genet 119:1507-1522 
Hillocks RJ (2012) Farming with fewer pesticides: EU pesticide review and resulting challenges for UK agriculture. Crop Prot 31:85-93

Igartua E, Gracia MP, Lasa JM, Medina B, Molina-Cano JL, Montoya JL, Romagosa I (1998) The Spanish Barley Core Collection. Genet Resour Crop Ev 45:475-481

Igartua E, Moralejo M, Casas AM, Torres L, Molina-Cano JL (2013) Whole-genome analysis with SNPs from BOPA1 shows clearly defined groupings of Western Mediterranean, Ethiopian, and Fertile Crescent barleys. Genet Resour Crop Ev 60:251-264

IBSC International Barley Genome Sequencing Consortium (2012) A physical, genetic and functional sequence assembly of the barley genome. Nature 491:711-716

Jackson LF, Webster RK (1976) Race differentiation, distribution, and frequency of Rhynchosporium secalis in California. Phytopathol 66:719-725

Jansen R, Stam P (1994) High resolution of quantitative traits into multiple loci via interval mapping. Genetics 136:1447-1455

Jensen J, Backes G, Skinnes H, Giese H (2002) Quantitative trait loci for scald resistance in barley localized by a non-interval mapping procedure. Plant Breeding 121:124-128

Kosambi DD (1944) The estimation of map distances from recombination values. Annals Eugenetics 12:172-175

Langridge P, Karakousis A, Kretschmer J, Manning S, Chalmers K (1996) Molecular relationship between barley varieties.

http://wheat.pw.usda.gov/ggpages/DEM/Polymorphism/Waite/Barley_dend.gif (accessed 26/02/2013)

Lasa JM (2008) Spanish Barley Core Collection. Monografias INIA: Serie Agricola, n25. ISBN 978-84-7498-526-9

Li HB, Zhou MX (2011) Quantitative trait loci controlling barley powdery mildew and scald resistances in two different barley doubled haploid populations. Mol Breeding 27:479-490

Li JZ, Sjakste TG, Röder MS, Ganal MW (2003) Development and genetic mapping of 127 new microsatellite markers in barley. Theor Appl Genet 107:1021-1027

Liu ZW, Biyashev RM, Saghai Maroof MA (1996) Development of simple sequence repeat DNA markers and their integration into a barley linkage map. Theor Appl Genet 93:869-876

Looseley ME, Newton AC, Atkins SD, Fitt BDL, Fraije B, Thomas WTB, Keith R, Lynott J, Harrap D (2012) Genetic basis of control of Rhynchosporium secalis infection and symptom expression in barley. Euphytica 184:47-56

Mayer KFX, Martis M, Hedley PE, Šimková H, Liu H, Morris JA, Steuernagel B, Taudien S, Roessner S, Gundlach H, Kubaláková M, Suchánková P, Murat F, Felder M, Nussbaumer T, Graner A, Salse J, Endo T, Sakai H, Tanaka T, Itoh T, Sato K, Platzer M, Matsumoto T, Scholz U, Dolezél J, Waugh R, Stein N (2011). Unlocking the barley genome by chromosomal and comparative genomics. Plant Cell 23:1249-1263

Muñoz-Amatriaín, M, Moscou MJ, Bhat PR, Svensson JT, Bartoš J, Suchánková P, Šimková H, Endo TR, Fenton RD, Lonardi S, Castillo AM, Chao S, Cistué L, Cuesta-Marcos A, Forrest KL, Hayden MJ, Hayes PM, Horsley RD, Makoto K, Moody D, Sato K, Vallés MP, Wulff BBH, Muehlbauer GJ, Doležel J, Close TJ (2011) An improved consensus linkage map of barley based on flow-sorted chromosomes and single nucleotide polymorphism markers. Plant Genome 4:238-249

Patil V, Bjørnstad A, Mackey J (2003) Molecular mapping of a new gene Rrs4CI11549 for resistance to barley scald (Rhynchosporium secalis). Mol Breeding 12:169-183

Paulitz TC, Steffenson BJ (2011) Biotic stress in barley: disease problems and solutions. In: Barley: Production, Improvement and Uses. SE Ullrich (ed) Blackwell Publishing Ltd, pp. 307-354

Penner GA, Tekauz A, Reimer E, Scoles GJ, Rossnagel BG, Eckstein PE, Legge WG, Burnett PA, Ferguson T, Helm JF (1996) The genetic basis of scald resistance in western Canadian barley cultivars. Euphytica 92:367-374 
Phillips D, Nibau C, Ramsay L, Waugh R, Jenkins G (2010) Development of a molecular cytogenetic recombination assay for barley. Cytogenet Genome Res 129:154-161

Pickering R, Ruge-Wehling B, Johnston PA, Schweizer G, Ackermann P, Wehling P (2006) The transfer of a gene conferring resistance to scald (Rhynchosporium secalis) from Hordeum bulbosum into $\mathrm{H}$. vulgare chromosome 4HS. Plant Breeding 125:576-579

Ponce-Molina LJ, Casas AM, Gracia MP, Silvar C, Mansour E, Thomas WBT, Schweizer G, Herz M, Igartua E (2012) Quantitative trait loci and candidate loci for heading date in a large population of a wide barley cross. Crop Sci 52:2469-2480

Ramsay L, Macaulay M, degli Ivanissevich S, MacLean K, Cardle L, Fuller J, Edwards KJ, Tuvesson S, Morgante M, Massari A, Maestri E, Marmiroli N, Sjakste T, Ganal M, Powell W, Waugh R (2000) A simple sequence repeat-based linkage map of barley. Genetics 156:1997-2005

Read BJ, Macdonald AF (1991) Hordeum vulgare (barley) cv. Yerong. Aus J Exp Agric 31:866866

Rostoks N, Mudie S, Cardle L, Russell J, Ramsay L, Booth A, Svensson J, Wanamaker S, Walia H, Rodriguez E, Hedley P, Liu H, Morris J, Close T, Marshall D, Waugh R (2005) Genomewide SNP discovery and linkage analysis in barley based on genes responsive to abiotic stress. Mol Gen Genomics 274:515-527

Sayed H, Kayyal H, Ramsay L, Ceccarelli S, Baum M (2002) Segregation distortion in doubled haploid lines of barley (Hordeum vulgare L.) detected by simple sequence repeat (SSR). Euphytica 225:265-272

Schweizer GF, Baumer M, Daniel G, Rugel H, Röder MS (1995) RFLP markers linked to scald (Rhynchosporium secalis) resistance gene Rh2 in barley. Theor Appl Genet 90:920-924

Schweizer G, Herz M, Mikolajewski S, Brenner M, Hartl L, Baumer M (2004) Genetic mapping of a novel scald resistance gene Rrs15CI8288 in barley. In: Proc 9th Int Barley Genet Symp, Brno, Czech Republic, 20-26 Jun 2004, pp 258-265

Shipton WA, Boyd WJR, Ali SM (1974) Scald of Barley. Rev Plant Pathol 53:839-861

Silvar C, Casas AM, Kopahnke D, Habekuß A, Schweizer G, Gracia MP, Lasa JM, Ciudad FJ, Molina-Cano JL, Igartua E, Ordon F (2010) Screening the Spanish barley core collection for disease resistance. Plant Breeding 129:45-52

Silvar C, Casas AM, Igartua E, Ponce-Molina LJ, Gracia MP, Schweizer G, Herz M, Flath K, Waugh R, Kopahnke D, Ordon F (2011) Resistance to powdery mildew in Spanish barley landraces is controlled by different sets of quantitative trait loci. Theor Appl Genet 123:1019-1028

Starling TM, Roane CW, Chi KR (1971) Inheritance of reaction to Rhynchosporium secalis in winter barley cultivars. Proc 2nd Int Barley Genetics Symp, Pullman, WA, 513-519

Stein N, Prasad M, Scholz U, Thiel T, Zhang H, Wolf M, Kota R, Varshney RK, Perovic D, Grosse I, Graner A (2007) A 1,000-loci transcript map of the barley genome: new anchoring points for integrative grass genomics. Theor Appl Genet 114:823-839

Thiel T, Michalek W, Varshney RK, Graner A (2003) Exploiting EST databases for the development of cDNA derived microsatellite markers in barley (Hordeum vulgare L.). Theor Appl Genet 106:411-422

Thirugnanasambandam A, Wright KM, Atkins SD, Whisson SC, Newton AC (2011) Infection of Rrs1 barley by an incompatible race of the fungus Rhynchosporium secalis expressing the green fluorescent protein. Plant Pathol 60:513-521

Thomas WTB, Powell W, Waugh R, Chalmers KJ, Barua UM, Jack P, Lea V, Forster BP, Swanston JS, Ellis RP, Hanson PR, Lance RCM (1995) Detection of quantitative trait loci for agronomic, yield, grain and disease characters in spring barley (Hordeum vulgare L.). Theor Appl Genet 91:1037-1047

van Ooijen JW (2004) MapQTL® 5, Software for the mapping of quantitative trait loci in experimental populations. Kyazma BV, Wageningen, Netherlands 
van Ooijen JW (2006) JoinMap 4, software for the calculation of genetics linkage maps in experimental populations. Kyazma, BV, Wageningen, Netherlands

Varshney RK, Grosse I, Hähnel U, Siefken R, Prasad M, Stein N, Langridge P, Altschmied L, Graner A (2006) Genetic mapping and BAC assignment of EST-derived SSR markers shows non-uniform distribution of genes in the barley genome. Theor Appl Genet 113:239250

Varshney RK, Marcel TC, Ramsay L, Russell J, Röder MS, Stein N, Waugh R, Langridge P, Niks RE, Graner A (2007) A high density barley microsatellite consensus map with 775 SSR loci. Theor Appl Genet 114:1091-1103

von Korff M, Wang H, Léon J, Pillen K (2005) AB-QTL analysis in spring barley. I. Detection of resistance genes against powdery mildew, leaf rust and scald introgressed from wild barley. Theor Appl Genet 111:583-590

VSN International (2011) Genstat for Windows 14th edition. VSN International, Hemel Hempstead, UK http:/www.vsni.co.uk/software/genstat?ref=genstat.co.uk (accessed 03/10/2011)

Wagner C, Schweizer G, Krämer M, Dehmer-Badani AG, Ordon F, Friedt W (2008) The complex quantitative barley-Rhynchosporium secalis interaction: newly identified QTL may represent already known resistance genes. Theor Appl Genet 118:113-122

Wallwork H, Grcic M (2011) The use of differential isolates of Rhynchosporium secalis to identify resistance to leaf scald in barley. Australasian Plant Pathol 40:490-496

Williams KJ, Bogacki P, Scott L, Karakousis A, Wallwork H (2001) Mapping a gene for scald resistance in barley Line 'B87/14' and validation of microsatellite and RFLP markers for marker-assisted selection. Plant Breeding 120:301-304

Xi K, Xue AG, Burnett PA, Helm JH, Turkington TK (2000) Quantitative resistance of barley cultivars to Rhynchosporium secalis. Can J Plant Pathol 22:221-227

Yun SJ, Gyenis L, Hayes PM, Matus I, Smith KB, Steffenson BJ, Muehlbauer GJ (2005) Quantitative trait loci for multiple disease resistance in wild barley. Crop Sci 45:2563-2572

Zaffarano PL, McDonald BA, Linde CC (2011) Two new species of Rhynchosporium. Mycologia 103:195-202

Zhan J, Fitt BDL, Pinnschmidt HO, Oxley SJP, Newton AC (2008) Resistance, epidemiology and sustainable management of Rhynchosporium secalis populations on barley. Plant Pathol 57:01-14

Zhan J, Yang L, Zhu W, Shang L, Newton AC (2012) Pathogen populations evolve to greater race complexity in agricultural systems - evidence from analysis of Rhynchosporium secalis virulence data. PlosOne 6 e38611 
Figure 1. Response of SBCC145×Beatrix and SBCC154×Beatrix DH lines to $R$. commune isolates 271 and LfL07. The Jackson and Webster (1976) scale extended by half steps was used. Vertical arrows indicate mean disease scores.

A and B: Both DH populations ( $n=522 /$ SBCC $145 \times$ Beatrix, $n=416$ SBCC154 $\times$ Beatrix $)$ were tested with isolate 271 .

$\mathrm{C}$ and D: Isolate LfL07 was used with those subpopulations genotyped with BOPA1 ( $\mathrm{n}=190 /$ SBCC145 $\times$ Beatrix, $\mathrm{n}=168 / \mathrm{SBCC} 154 \times$ Beatrix $)$.

Figure 2. A. Integrated map of the QTL region of chromosome $3 \mathrm{H}$ derived from $872 \mathrm{DH}$ lines coming from the SBCC $145 \times$ Beatrix and SBCC $154 \times$ Beatrix populations. The map covers the region of the Rrs1 locus. Rrs1 itself was mapped as a binary trait. B. Close-up view of the region around Rrs1.

Figure S1. Response of SBCC145×Beatrix and SBCC154×Beatrix DH lines to R. commune isolates 271 and LfL07 for the subpopulations genotyped with BOPA1 ( $\mathrm{n}=190 / \mathrm{SBCC} 145 \times$ Beatrix, $\mathrm{n}=168 /$ SBCC154×Beatrix). The Jackson and Webster (1976) scale extended by half steps was used. In addition occurrence of the marker allele of 11_0205 is shown (red "SBCCxxx", blue "Beatrix" allele). Black vertical arrows indicate mean disease scores, red vertical arrows the resistant parent SBCC145 or SBCC154 respectively and blue vertical arrows the susceptible parent Beatrix. A) SBCC145×Beatrix, isolate 271. B) SBCC154×Beatrix, isolate 271. C) SBCC145×Beatrix, isolate LfL07. D) SBCC154×Beatrix, isolate LfL07.

Figure S2. Genetic map of the population SBCC154 x Beatrix, genotyped with BOPA1.

Figure S3. MQM LOD scans for resistance scores to R. commune isolates 271 and LfL07 in 190 DH lines of SBCC145×Beatrix and 142 DH lines of SBCC154×Beatrix. The horizontal dotted lines and the numbers above them indicate the significance threshold for QTL detection based on an experiment-wise error rate of less than $5 \%$, estimated with 1,000 permutations. 


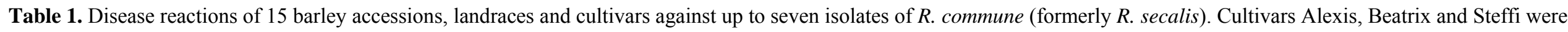
included as susceptible controls.

\begin{tabular}{|c|c|c|c|c|c|c|c|c|c|}
\hline \multirow{3}{*}{$\begin{array}{l}\text { Barley lines } \\
\text { (references) }\end{array}$} & \multicolumn{8}{|c|}{ Rhynchosporium commune isolates $\dagger$} & \multirow{3}{*}{$\begin{array}{l}\text { R-Gene(s) } \\
\text { (according to } \\
\text { literature) }\end{array}$} \\
\hline & & & & & & Mean & & & \\
\hline & S147-1 & Rhy 17 & Rhy174 & UK7 & LfL07 & $\begin{array}{c}\text { S147-1 - } \\
\text { LfL07 }\end{array}$ & $332 \mathrm{a}$ & 385 & \\
\hline SBCC $145^{(1)}$ & 0.0 & 0.0 & 0.5 & 0.5 & 0.0 & 0.2 & 0.0 & 4.0 & $R r s 1_{R h 4}$ \\
\hline $\mathrm{SBCC} 154^{(1)}$ & 0.0 & 0.0 & 0.6 & 0.6 & 0.0 & 0.2 & 0.0 & 4.0 & $\operatorname{Rrs} 1_{R h 4}$ \\
\hline Atlas $^{(2,3,4,10)}$ & 0.1 & 0.3 & $0.8^{*}$ & 0.8 & $0.9 *$ & 0.6 & 4.0 & 4.0 & Rrs2 \\
\hline CIho $2235^{(5,10)}$ & 0.3 & 0.2 & 0.4 & 0.2 & 1.1 & 0.4 & - & - & Rrs2 \\
\hline Pewter $^{(5,10)}$ & 0.9 & 0.8 & 1.2 & 0.6 & 1.3 & 0.9 & - & - & Rrs2 \\
\hline Escald. $15^{(5,10)}$ & 0.3 & 0.1 & $0.7 *$ & 1.3 & - & 0.6 & - & - & $\operatorname{Rrs} 2$ \\
\hline CIho $8288^{(8,9)}$ & 1.3 & 0.0 & 0.6 & 0.5 & 1.2 & 0.7 & - & - & Rrs15 \\
\hline Atlas $46^{(3,4,5,10)}$ & 0.4 & 0.3 & 0.0 & 0.0 & 0.0 & 0.1 & 4.0 & 0.0 & $R r s 1+\operatorname{Rrs} 2$ \\
\hline Osiris $^{(3,4,5,10)}$ & 0.0 & 0.0 & 0.4 & 0.3 & 0.0 & 0.1 & 0.0 & 3.5 & $R r s 1_{R h 4}+\operatorname{Rrs} 2$ \\
\hline PI $452395^{(5,10)}$ & 0.5 & 0.2 & 0.0 & 0.1 & 0.0 & 0.2 & - & - & $R r s 1+R r s 2$ \\
\hline CIho $3515^{(4,5,6)}$ & 0.0 & 0.0 & 0.4 & 0.3 & 0.1 & 0.2 & 0.0 & 1.0 & $R r s 1_{R h 4}+R r s 13$ \\
\hline $\operatorname{Triton}^{(9)}$ & 0.1 & 0.0 & 0.0 & 0.0 & 0.0 & 0.0 & - & - & $R r s 1+R r s 15$ \\
\hline Alexis & 4.0 & 4.0 & 4.0 & 3.9 & 4.0 & 4.0 & - & - & Susceptible \\
\hline Beatrix & 4.0 & 4.0 & 3.9 & 4.0 & 4.0 & 4.0 & - & - & Susceptible \\
\hline Steffi & 4.0 & 4.0 & 4.0 & $4.0 *$ & 4.0 & 4.0 & - & - & Susceptible \\
\hline
\end{tabular}

${ }^{\dagger}$ Isolates S147-1 - LfL07 were tested at LfL in Freising in the greenhouse at early three leaf stage with four seeds/accession in two replications, as described in Material and

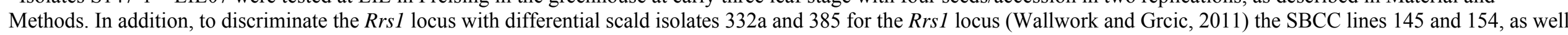
as four reference lines were tested at SARDI following the procedures explained in material and methods.

* Plants were tested in a single greenhouse test with four plants.

- not determined.

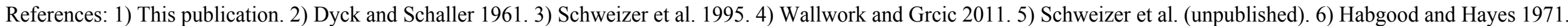
7) Bjørnstadt et al. 2002. 8) Schweizer et al. 2004. 9) Wagner et al. 2008. 10) Hanemann et al. 2009. 
Table 2. Summary of QTLs for scald resistance detected in the SBCC145×Beatrix and SBCC154×Beatrix DH populations in response to inoculation with $R$. commune isolates 271 and LfL07. The columns QTL and Interval show the position of the peak and the 2-LOD confidence intervals. $R^{2}$ is the percentage of phenotypic variance explained by the QTL. A negative value for the additive effect indicates that the allele from SBCC145 or SBCC154 reduced the value of the trait.

\begin{tabular}{lllllllll}
\hline Population & QTL No. & $\begin{array}{l}\text { Linkage } \\
\text { group }\end{array}$ & $\begin{array}{l}\text { QTL } \\
\text { (cM) }\end{array}$ & $\begin{array}{l}\text { Interval } \\
\text { (cM) }\end{array}$ & $\begin{array}{l}\text { Closest } \\
\text { marker }\end{array}$ & $\begin{array}{l}\text { LOD } \\
\text { score }\end{array}$ & $\boldsymbol{R}^{2} \%$ & $\begin{array}{l}\text { Additive } \\
\text { effect }\end{array}$ \\
\hline SBCC145×Beatrix & isolate 271 & & & & & & & \\
& 1 & $2 \mathrm{H}$ & 31.4 & $30.3-33.4$ & $11 \_1175$ & 3.6 & 0.5 & -0.12 \\
& 2 & $3 \mathrm{H}$ & 70.4 & $70.0-72.1$ & $11 \_0205$ & 141.3 & 96.2 & -1.68 \\
& 3 & $4 \mathrm{H}$ & 53.1 & $52.5-53.9$ & $11 \_1316$ & 10.6 & 1.2 & -0.88 \\
& isolate LfL07 & & & & & & & \\
& 1 & $3 \mathrm{H}$ & 70.0 & $68.0-70.8$ & $11 \_0205$ & 73.4 & 84.3 & -1.52 \\
\hline SBCC154×Beatrix & isolate 271 & & & & & & & \\
& 1 & $2 \mathrm{H}$ & 37.1 & $35.1-37.5$ & $11 \_1159$ & 2.8 & 1.5 & -0.19 \\
& 2 & $3 \mathrm{H}$ & 70.3 & $72.0-73.1$ & $11 \_0010$ & 61.5 & 88.3 & -1.53 \\
& isolate LfL07 & & & & & & & \\
& 1 & $3 \mathrm{H}$ & 72.5 & $72.0-73.1$ & $11 \_0010$ & 37.8 & 73.1 & -1.14 \\
\hline
\end{tabular}

Table 3. Mean scald resistance values against $R$. commune isolate 271 in the subpopulation SBCC145 $\times$ Beatrix for the $\mathrm{DH}$ lines grouped according to the haplotypes presented at the markers closest to the QTL peaks.

\begin{tabular}{llrl}
\hline Haplotype $^{\mathbf{1}}$ & $\mathbf{n}$ & $\begin{array}{c}\text { Scald resistance } \\
\text { scores }\end{array}$ & \\
\hline$a a a$ & 15 & 0.33 & $\mathrm{a}$ \\
$a b a$ & 12 & 0.39 & $\mathrm{ab}$ \\
$b a a$ & 27 & 0.58 & $\mathrm{~b}$ \\
$b b a$ & 19 & 1.00 & $\mathrm{c}$ \\
$a a b$ & 25 & 3.68 & $\mathrm{~d}$ \\
$a b b$ & 15 & 4.00 & $\mathrm{e}$ \\
$b a b$ & 34 & 3.97 & $\mathrm{e}$ \\
$b b b$ & 35 & 3.98 & $\mathrm{e}$ \\
\hline
\end{tabular}

${ }^{1}$ Haplotypes for alleles at markers 11_1175 (2H), 11_1316 (4H) and 11_0205 (3H);

$\mathrm{a}=$ SBCC145 allele, $\mathrm{b}=$ Beatrix allele.

${ }^{2}$ Means followed by the same letter are not significantly different (LSD, $\mathrm{P}<0.05$ ). 
Table S1. CAPS markers derived from BOPA1 markers.

\begin{tabular}{|c|c|c|c|}
\hline Marker & Left primer $\left(5^{\prime}-3^{\prime}\right)$ & Right primer $\left(5^{\prime}-3^{\prime}\right)$ & $\begin{array}{l}\text { Restriction } \\
\text { enzyme }\end{array}$ \\
\hline 11_0010 & CGACGAGGAAGATGATGACC & TCAGCACACCACTCCAATGT & HpaII \\
\hline $11 \_0823^{1}$ & CAGTCACCCAAACCTTCGAG & TACATGCGCATCTTGTGATG & TaqI \\
\hline 11_0205 & GCATTTGGAGGAGTCTGCAT & ACAAACACTTGGCGGCTAAT & MaeI \\
\hline 11_0315 & GGACAAGTTCAGCACACAGC & ACGAAGTCATGGCAAGCTCT & AciI \\
\hline 11_1476 & CATCGGCAAAGATAACTCCTG & GCAGAGGAGACAATGGGCTA & AciI \\
\hline
\end{tabular}

${ }^{1}$ Polymorphic only in SBCC154×Beatrix.

Table S2. SSR markers assayed in both populations.

Table S3. Markers showing segregation distortion in the region of chromosome $3 \mathrm{H}$ encompassing the scald resistance QTL. 

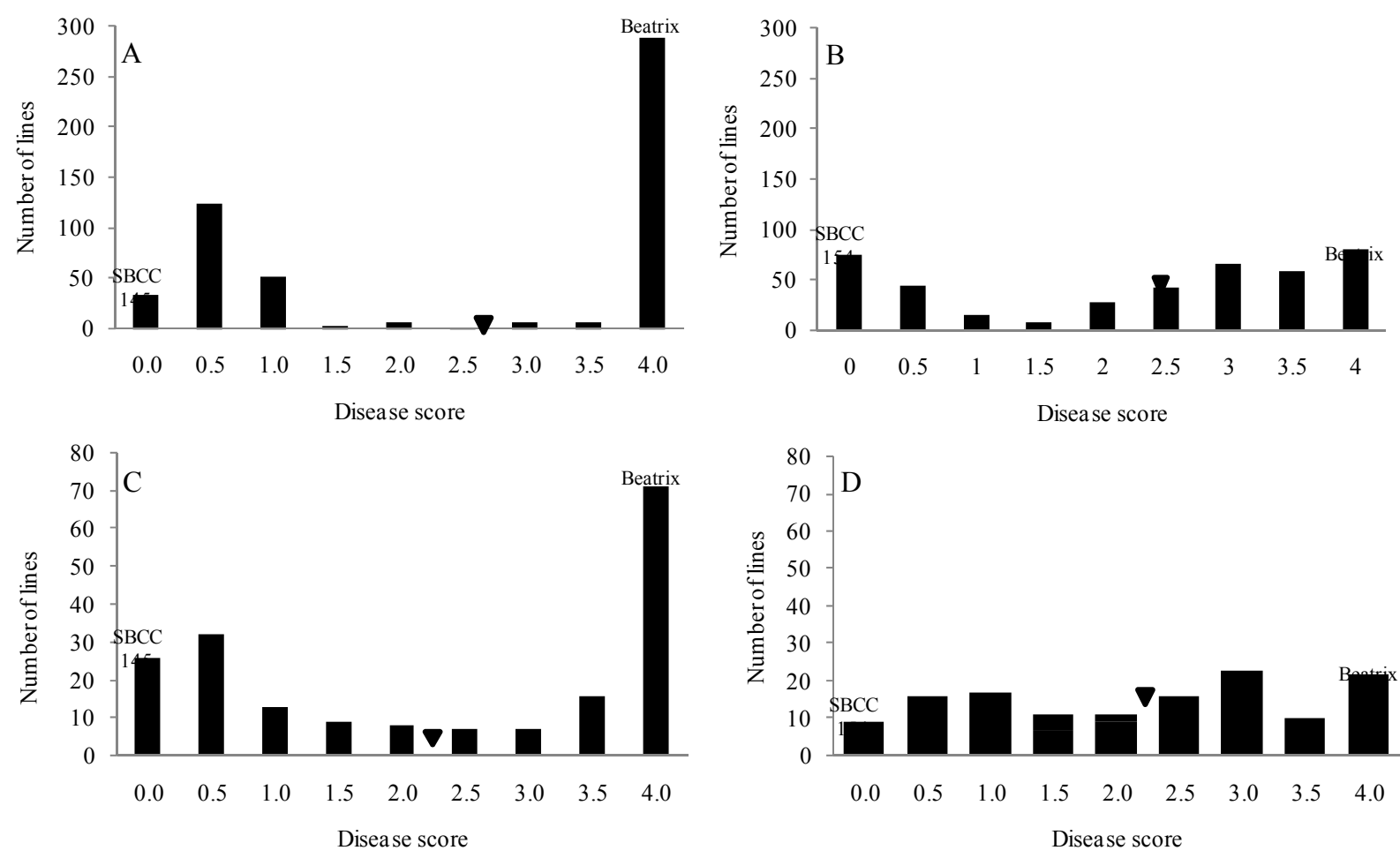

Figure 1. 
A

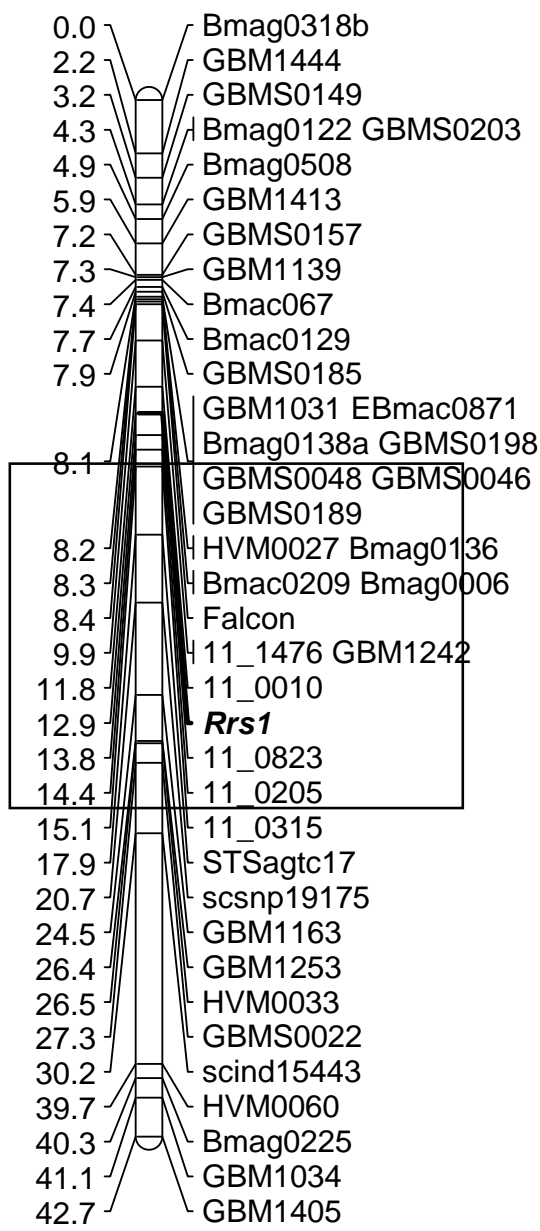

B

\begin{tabular}{|c|c|}
\hline $\begin{array}{l}8.2 \\
8.3 \\
8.4 \\
9.9 \\
11.8 \\
12.9 \\
13.8 \\
14.4 \\
15.1 \\
17.9 \\
20.7\end{array}$ & 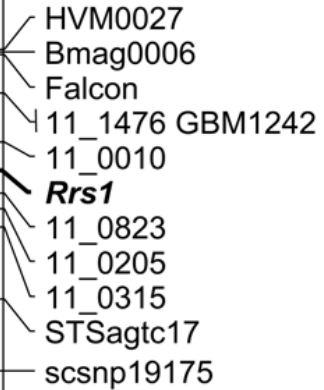 \\
\hline
\end{tabular}

Figure 2. 